\title{
Iodine concentration of milk-alternative drinks available in the UK
}

\author{
S.C. Bath ${ }^{1}$, S. Hill ${ }^{2}$, H. Goenaga-Infante ${ }^{2}$, S. Elghul ${ }^{1}$ and M.P. Rayman ${ }^{1}$ \\ ${ }^{1}$ University of Surrey, Guildford, Surrey, GU2 $7 X H$ and ${ }^{2} L G C$, Teddington, Middlesex, TW11 OLY
}

Iodine deficiency is present in certain groups of the population, including women of childbearing age and pregnant women ${ }^{(1)}$ which is of concern as deficiency during pregnancy is associated with poorer cognition in the offspring ${ }^{(2)}$. UK cows' milk is a rich source of iodine and, together with dairy products, is the principal source of iodine intake. Sales of milk alternatives (e.g. soya/almond/rice drinks) increased by $155 \%$ between 2011 and 2013 in the $\mathrm{UK}^{(3)}$. As consumers may be choosing milk-alternative drinks in place of iodine-rich milk, we aimed to measure the iodine content of these replacement products.

We selected milk-alternative drinks for laboratory analysis according to the following selection criteria: drinks that were (i) longlife, (ii) unsweetened, (iii) unflavoured, and (iv) widely available from major retail outlets (i.e. not those only available via online-only health shops). In addition, we included chilled products from the market leader, and sweetened drinks where these were labelled as "original" and therefore likely to be a popular choice with consumers. Iodine-fortified drinks (soya, oat, and rice) sold by one brand (Marks and Spencer) were also included $(\mathrm{n}=3$ ). For comparison, we also analysed conventional semi-skimmed cows' milk from five supermarket chains. Iodine concentration was measured at LGC using ICP-MS after alkaline digestion; a certified reference material (ERM-BD150 Skimmed Milk Powder) was used to assess the accuracy of the results.

The conventional cows' milk samples $(n=5)$ had a median iodine concentration of $438.0 \mathrm{ng} / \mathrm{g}$. The iodine concentration of the seven types of milk-alternative drinks was low with values ranging from 0.9 to $4.9 \%$ of that of cows' milk iodine concentration (Table). A considerable number of the milk-alternative samples $(\mathrm{n}=13 ; 27.7 \%)$ had an iodine concentration that was below the limit of quantification for the assay $(3.6 \mathrm{ng} / \mathrm{g})$. The iodine-fortified drinks had a higher iodine concentration i.e. $280 \mathrm{ng} / \mathrm{g}$ for soya, $287 \mathrm{ng} / \mathrm{g}$ for oat, and $266 \mathrm{ng} / \mathrm{g}$ for rice.

\begin{tabular}{|c|c|c|c|c|c|}
\hline & \multicolumn{4}{|c|}{ Iodine concentration of unfortified milk-alternative drinks (ng/g) } & \multirow{2}{*}{$\begin{array}{l}\text { Iodine concentration as a percentage of } \\
\text { that of conventional cows' milk }\end{array}$} \\
\hline & $\mathrm{n}$ & Median & $25-75$ th percentile & Min, $\max$ & \\
\hline Soya & 13 & $12 \cdot 7$ & $11 \cdot 1,13 \cdot 8$ & $<3 \cdot 6,14 \cdot 4$ & $2 \cdot 9$ \\
\hline Almond & 11 & $5 \cdot 6$ & $4 \cdot 6,14 \cdot 0$ & $<3 \cdot 6,18 \cdot 0$ & $1 \cdot 3$ \\
\hline Coconut & 6 & $8 \cdot 1$ & $4 \cdot 4,17 \cdot 4$ & $<3 \cdot 6,18 \cdot 2$ & 1.9 \\
\hline Oat & 5 & $7 \cdot 9$ & $3 \cdot 6,37 \cdot 4$ & $<3 \cdot 6,68 \cdot 3$ & $1 \cdot 2$ \\
\hline Rice & 4 & $4 \cdot 7$ & $3 \cdot 6,7 \cdot 4$ & $<3.6,8 \cdot 5$ & $0 \cdot 9$ \\
\hline Hazelnut & 3 & $4 \cdot 4$ & NA & $<3.6,5 \cdot 2$ & $1 \cdot 1$ \\
\hline Hemp & 2 & $15 \cdot 9$ & NA & $7 \cdot 0,36 \cdot 3$ & $4 \cdot 9$ \\
\hline
\end{tabular}

Milk-alternative drinks on the UK market are naturally low in iodine. Although many milk-alternative drinks are fortified with calcium, only one brand fortified some of their drinks with iodine at the time of our study. Individuals who consume unfortified drinks in place of cows' milk may be at risk of iodine deficiency and need to aware of their low iodine content and the necessity of consuming other iodine sources, for example fish and eggs.

S.C. Bath was supported by an MRC Population Health Scientist Fellowship (MR/K02132X/1). The study was partly supported by the BBC for its BBC1 programme, "The Truth About Health Foods".

1. Bath SC et al. (2015) Environ Geochem Health 37, 619-629.

2. Bath SC et al. (2013) Lancet 382, 331-337.

3. Mintel (2014) Available at: http://www.mintel.com/press-centre/food-and-drink/is-it-game-set-and-match-for-traditional-cream-at-years-wimbledon (accessed 16 July 2014). 